\title{
Development and Testing of Hot Cold Tumbler Operating on Peltier Effect
}

\author{
Robin Lee, Chong Chee Kiong, Chin Tin Huang, Ratnakar Kulkarni \\ Faculty Engineering Technology, University of Malaysia, Pahang \\ kulkarni@ump.edu.my
}

\begin{abstract}
Use of Peltier effect for cooling is not new. Various attempts have been made to generate cooling using Peltier effect. Occasionally use of this effect for heating applications is also reported. This paper reports the development and testing of a hot cold tumbler that is capable of heating as well as cooling of a 300 cc can of water/tea/coffee or any other liquid. The compact design makes this tumbler portable and can be carried out without any inconvenience. Use of battery makes it possible to use this at remote places or where electric supply is not readily available. The testing showed positive results and tumbler was capable of heating drink can up to $60^{\circ} \mathrm{Cand}$ cooling was achieved up to $20^{\circ} \mathrm{C}$ within a span of 30 minutes. To reduce this time it was suggested to increase the Peltier chip capacity and solar power to recharge the battery.
\end{abstract}

Keywords: Peltier Effect, Thermoelectric Effect

\section{INTRODUCTION}

There is often need of heating and cooling of soft drinks. Normally drinks are kept in a refrigerator for cooling and microwave heaters, resistance heaters and traditional gas burners are used for heating. During camping or at remote site where electrical supply is not available it is difficult to use such instruments. A portable device which is battery operated and has an option to recharge the batteries with solar energy could be the best answer for this type of situation. The Peltier effect is the presence of heating or cooling at an electrified junction of two different conductors and is named after French physicist Jean Charles Athnase Peltier who discovered it in 1834. When a current is made to flow through a junction between two conductors, A and B, heat may be generated or removed at the junction. Figure 1 explains this effect. The equipments working on this effect can be used to generate cooling effect and also for the generation of heating effect.

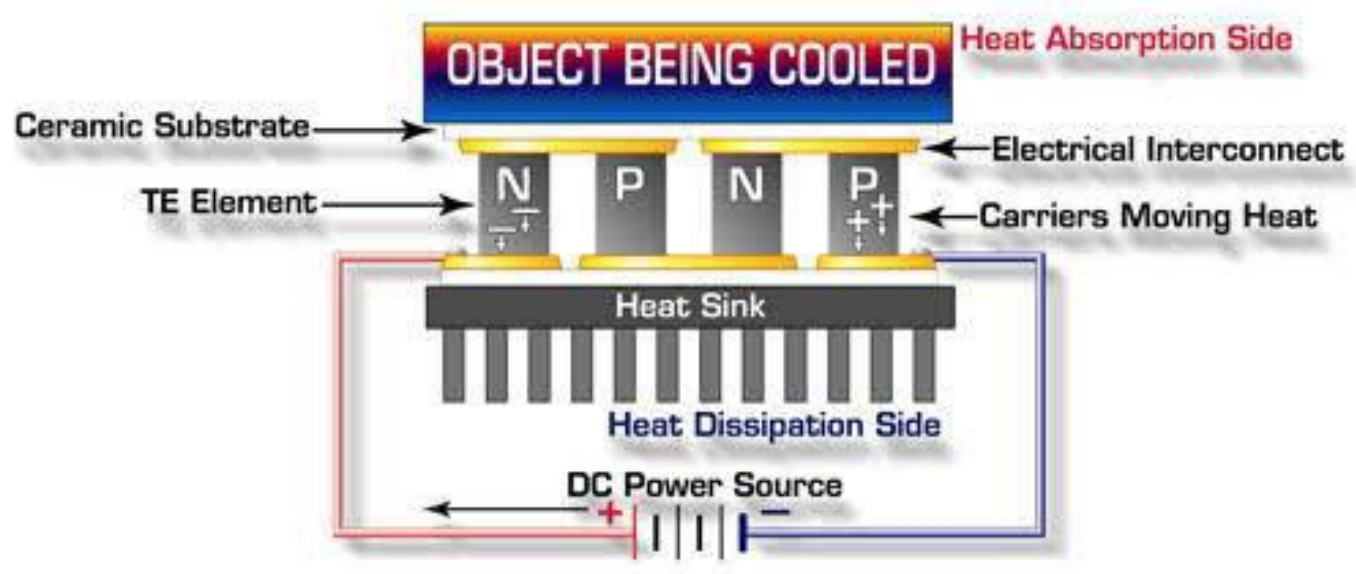

Fig 1. Principle of thermoelectric module 


\section{PELTIER EFFECT FOR GENERATION OF HEATING, COOLING EFFECT}

In past many investigators have reported about using Peltier effect for the generation of cooling effect. Nikam and Hole [1] have taken a review of use of Peltier effect for cooling applications. Use of Peltier effect for cooling can be used in following two ways:

$>$ Integrated use of Peltier effect and

$>$ Direct use of Peltier effect.

This effect as produce direct effect for cooling or heating and can use Peltier module in existing system to increase the performance or COP of the system. In a conventional vapor compression system, with a traditional condenser that includes a sub-cooler, liquid refrigerant leaving the subcooler only can be cooled to the temperature level of the heat sink. Using a thermoelectric element for sub-cooling, the liquid refrigerant can be subcooled significantly at a COP that exceeds that of the original vapor compression system. Jangonda et al [2] have reported on the Peltier effect applications. Following four applications are discussed.

$>$ Thermoelectric generator

$>$ Thermoelectric cooler

$>$ Water condensation using thermoelectric cooler

$>$ Medical Freezer

Sonkhede and Pathrikar [3] reported on the analysis of a portable refrigeration system for medical applications. They proposed a system with a Peltier module, microcontroller and power supply unit. In the analysis they worked out $\Delta \mathrm{T}_{\max }$ (the temperature difference between the hot and cold junction) and Qmax (Maximum heat transfer) for the given hot junction temperature and current passing through the circuit. They showed that the system achieves $40 \%$ to $60 \%$ of cooling effect compared to conventional refrigerator. However this paper discussed theoretical analysis part and no practical/field data was presented.

He et al [4] reported on theoretical and experimental investigation on a thermoelectric cooling and heating system driven by solar energy. The main idea of their work was study the building integrated solar photovoltaic/thermal (BIPV/T) technology in the application of low-carbon buildings. Compared with the thermoelectric refrigerator, the system can cool the room with cooling mode of thermoelectric powered by PV/T modules, get hot water using heat pipes and PV/T modules in summer, and in winter heat the room with heating mode of thermoelectric, PV/T modules being power and heat source simultaneously. A simulation study of the system was also carried out and they reported the attainment the COP up to 0.45. Chang et al [5] carried out an experimental investigation of thermoelectric air-cooling module. The experimental parameters considered were heat load of heat source and input current for thermos electric chip(TEC). The study quantified the thermal performances under every situation by thermal resistance network. The thermoelectric module and experimental set up used by them is shown below.

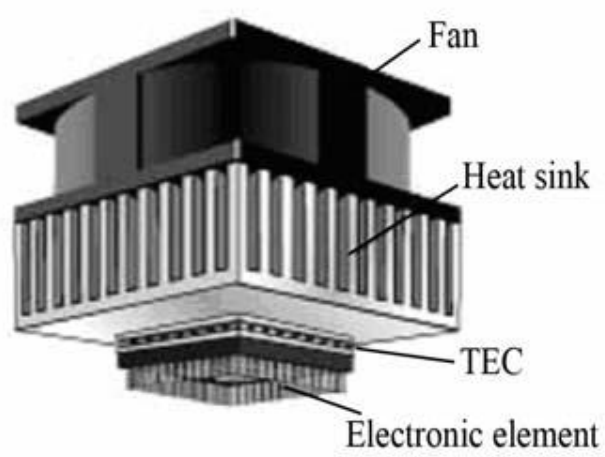

Fig 2: The thermoelectric cooling module with an air-cooling heat sink [5] 
Their study concluded that with increasing heating power of heat source, TEC resistance increases and heat sink resistance decreases. Including these two effects, the overall resistance grows with the increase of heating power.

Bo and Yawen [6] presented a design of portable bottle cooler. Peltier effect was used to obtain the cooling effect. The container material suggested was plastic with polyurethane foam as an insulation and aluminium foil as a reflector. Battery and module selection was made with an input parameter of 8 minutes time to cool 4 cans of beverage. Their design seems to have take all related parameters into consideration, however it was a theoretical study and no practical testing data is reported.

Ammanath and Radha [7] in their paper have discussed on fabrication of thermoelectric module operating on solar energy. A portable thermos-electric system for both cooling and heating applications was fabricated. The storage capacity of the box was 4.71 and three no. of thermoelectric modules with $45 \mathrm{~W}$ capacity of each were used. $50 \mathrm{~W}$ solar panels with battery were used as a power source. Their results show that system performed reasonably well, the temperature inside the cod box obtained was $14.5^{\circ} \mathrm{C}$ and the temperature inside the hot box obtained was $58^{\circ} \mathrm{C}$ for 2 hours.

The above discussion shows that use of Peltier effect for the generation of heating and cooling effects has been successfully attempted. Various applications have been developed. But simultaneous generation of heating and cooling effect has been rarely reported. Some experimental data is available but that is not adequate as a guideline for further researchers.

The current research work aims to develop a tumbler that heats and cools drinking water and working on Peltier effect without using wired electrical supply. With a single selection on the button, users are able to make the favourite hot or cold drinks and it is portable. Hence, it's applicable to use even on high terrain or during camping

\section{HOT COLD TUMBLER MODEL}

The hot cold tumbler model was fabricated with three compartments inside; one to accommodate liquid bottle/container, other for the electrical parts and the third one for Peltier module and heat sink. The following table shows the main parts and their details.

Table 1: Part Details of Tumbler

\begin{tabular}{|l|l|l|}
\hline Sr No & Part Name & Details \\
\hline 1 & Outer Body & Made of SS with 27 cm height \\
\hline 2 & Inner Container & SS with 300 cc capacity, 10 cm height \\
\hline 3 & Heat Sink & Aluminum \\
\hline 4 & Battery & $\begin{array}{l}4 \text { Nos LiFePo4 Polymer Cells } 3.2 \mathrm{~V} \\
\text { each }\end{array}$ \\
\hline 5 & Insulation & Thermocole \\
\hline 6 & Peltier Module & 3 Nos. Specs are given in Table 2 \\
\hline 7 & Electricals & DPDT switch, controller etc. \\
\hline
\end{tabular}

Table 2: Specifications of the TEC1-12706 Peltier Module

\begin{tabular}{|c|c|c|}
\hline Hot Side Temperature, ${ }^{\circ} \mathrm{C}$ & 25 & 50 \\
\hline Qmax, Watts & 50 & 57 \\
\hline Delta Tmax, ${ }^{\circ} \mathrm{C}$ & 66 & 75 \\
\hline Imax, Amps & 6.4 & 6.4 \\
\hline Vmax, Volts & 14.4 & 16.4 \\
\hline Resistance, Ohms & 1.98 & 2.30 \\
\hline
\end{tabular}


INTERNATIONAL JOURNAL OF ENGINEERING TECHNOLOGY AND SCIENCES (IJETS) Vol.7 (1) June 2017 DOI: http://dx.doi.org/10.15282/ijets.7.2017.1.13.1075

Figure 3 shows the finished tumbler model; this photograph was taken while testing.

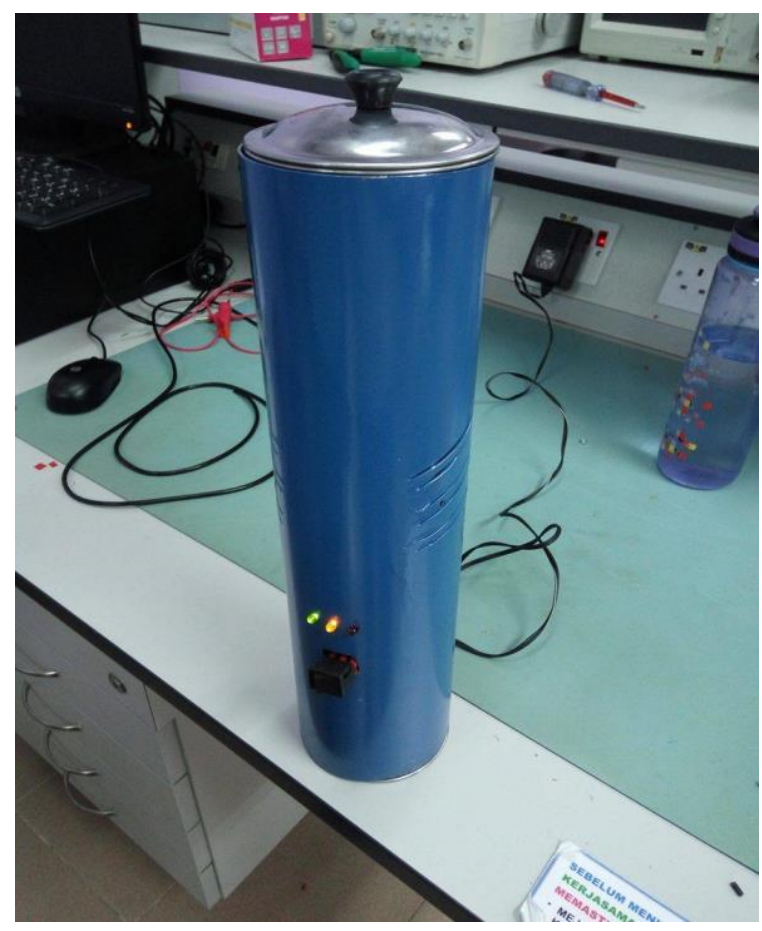

Figure 3: Assembly of the Hot Cold Tumbler

\section{PERFORMANCE TESTING AND RESULTS}

The testing of module was carried out in two phases; first for heating cycle and then by changing the switch position for cooling cycle. The inner container was filled with $300 \mathrm{cc}$ of water and the switch was put on. The temperature time history was recorded. It took about 35 minutes to heat the water from $26^{\circ} \mathrm{C}$ to $60^{\circ} \mathrm{C}$.

Table 3: Temperature Time History (Heating Cycle)

\begin{tabular}{|c|c|}
\hline Time (minutes) & Temperature $\left({ }^{\circ} \mathrm{C}\right)$ \\
\hline 0 & 26.0 \\
\hline 5 & 30.0 \\
\hline 10 & 35.0 \\
\hline 15 & 40.0 \\
\hline 20 & 45.0 \\
\hline 25 & 50.0 \\
\hline 30 & 55.0 \\
\hline 35 & 60.0 \\
\hline
\end{tabular}

Later on the tumbler was tested in cooling cycle. Time required to cool drink from $26^{\circ} \mathrm{C}$ to $20^{\circ} \mathrm{C}$. Following table (no.4) shows the cooling cycle data. 
INTERNATIONAL JOURNAL OF ENGINEERING TECHNOLOGY AND SCIENCES (IJETS) Vol.7 (1) June 2017

DOI: http://dx.doi.org/10.15282/ijets.7.2017.1.13.1075

Table 4: Temperature Time History (Cooling Cycle)

\begin{tabular}{|c|c|}
\hline Time (minutes) & Temperature $\left({ }^{\circ} \mathrm{C}\right)$ \\
\hline 0 & 26.0 \\
\hline 5 & 25.5 \\
\hline 10 & 25.0 \\
\hline 15 & 24.5 \\
\hline 20 & 24.0 \\
\hline 25 & 22.0 \\
\hline 30 & 21.0 \\
\hline 35 & 20.0 \\
\hline
\end{tabular}

\section{DISCUSSION AND CONCLUSION}

The tests carried out on tumbler show that it can work the way it was designed for, i.e. for heating and cooling of the liquids. The time required for heating and cooling was about 35 minutes that is a bit higher. There are two options to ease out this problem. One is to increase the capacity of thermoelectric module. This will increase the cost and also the battery size. There is limitation on battery size for portable gadgets. Use of solar panel for power supply can reduce the battery size, which seems to be viable option. The second option is instead of using this product for heating or cooling, use it for maintaining the temperature. In this case it will have just to compensate for heat gain or heat loss from the product. The future design of this product should take this point into consideration and can modify the size and layout accordingly.

Acknowledgement: The authors would like to express their gratitude towards Faculty Engineering Technology, University of Malaysia, Pahang for the financial support for the purchase of raw material and bought out items.

\section{REFERENCES}

[1] Nikam Ajitkumar and Hole Jitendra, 'A Review on Use of Peltier Effect' Pratibha: International Journal of Science, Spirituality, Business and Technology, Vol 2, No 2, 2014

[2] Jangonda Chetan, Patil Ketan, Kinikar Avinash, Bhokare Raviraj and Gawali M, ' Review of Various Applications of Thermoelectric Module', International Journal of Innovative Research in Science, Engineering and Technology, Vol 5, No 2, 2016.

[3] Sonkhede Prashant, Pathrikar A,'Portable Thermoelectric Refrigeration System for Medical Application' International Journal of Innovative Research in Computer and Communication Engineering, Vol 4, No 3, 2016.

[4] He Wei, Jhou Jinzhi, Hou Jingxin, Chen Chi and Ji Jie,' Theoretical and experimental investigation on a thermoelectric cooling' Applied Energy 107 (2013) 89-97, 2013.

[5] Chang Yu-Wei, Cheng Chiao-Hung, Wu Wen-Fang and Chen Sih-Li, 'An Experimental Investigation of Thermoelectric Air-Cooling Module' International Journal of Mechanical, Aerospace, Industrial, Mechatronic and Manufacturing Engineering Vol:1, No:9, 2007.

[6] Bo Liang and Yawen Chen, 'Portable Beer Can Cooler' Bachelor Thesis, Saimaa University of Applied Sciences Technology, Lappeenranta, Finland, 2010.

[7] Ammanath P and Radha K K,' Fabrication of Thermo Electric Module for Cooling and Heating Applications Using Solar Energy' International Journal of Science and Research, Vol 4, No.7, 2015 